\title{
A Framework for Results Based Management to the Public Sector in Egypt: Challenges and Opportunities
}

\author{
Dr. Wael Omran Aly \\ Associated Professor of Public Administration \\ High Institute of Computer Sciences and Information Systems \\ New Cairo Academy- Egypt \\ E. mail: wael.omran@ymail.com
}

Doi:10.5296/ jpag.v5i4.8406 URL: http://dx.doi.org/10.5296/ jpag.v5i4. 8406

\begin{abstract}
After the Second World War, the newly emerged independent third world countries faced immense problems such as poverty, illiteracy, poor health, low agriculture and industrial productivity and social instability. The idea of development administration was born with the above-stated pragmatic concern. Since then, third world countries strived to adopt development administration principles and techniques; in order to transform their conventional traditional public administration into modern development administration that can lead the prospective development.
\end{abstract}

Such conventional public administration deals with regulatory aspects of administration such as law and order, judicial administration and revenue collection, development administration is concerned with the socio-economic developmental activities.

Thus, traditional public administration is structure-oriented while developmental administration is action- oriented. Many third world countries failed in realizing such desired shift by converting its conventional public administration to effective development administration; able to achieve the intended national development via the formulation and the implementation of plans, policies, programs and projects necessary for sustainable development purposes. Such bad governance had led the people to go up against such government; as it happens lately in some Arab countries like Egypt and Tunisia.

Therefore, the public sector in Egypt need to be deregulated, a new results-based management is a must; to hold managers accountable. This is a fundamental change: holding managers accountable for what they do, not how they do it. The public sector reform initiatives (especially the New Public management -NPM) have resulted in changing the 
accountability concept; from accountability in terms of procedural compliance to accountability in terms of efficiency and results (effectiveness and cost effectiveness).

Keywords: Results based management, conventional public administration, development administration, public sector, new public management, good governance.

\section{Introduction}

For sustained development effectiveness, countries need to be able to manage their own development processes so that they can use their resources for the greatest development impact. They need to have a public sector that delivers essential services economically, efficiently, and effectively. An effective public sector builds strong financial and non-financial partnerships with other development players as donors, private sector, and civil society. It also reinforces country ownership in driving development processes and strengthens accountability for results.

Countries' weak public sector management (PSM) systems are often the key factor constraining the delivery and assessment of development initiatives. While the international focus on managing for development results (MfDR) has increased the need for these systems to be robust, many PSM capacity development initiatives have been short-term and unsustainable. Moreover, countries often see such capacity initiatives as supply-driven, imposing international good practice rather than building on the country's own systems (Nagy Hanna \& others, 2010).

In the late 1990s, the UN system adopted results-based management (RBM) to improve the effectiveness and accountability of UN agencies. This shift towards RBM was accompanied by increasing UN interagency collaboration and interaction that seek to respond to UN reform and the greater harmonization of UN programs with national priorities. A solid RBM system rests on what is commonly referred to as a 'life cycle' where results are central to planning, implementation, monitoring and evaluation, reporting and ongoing decision-making. By focusing on 'results' rather than 'activities', RBM helps countries to better articulate their vision and support for expected results and to better monitor progress using indicators, targets and baselines. Results based reports also help the public organizations, stakeholders and funding agencies to better understand the impact (outcomes) that a given program or project is having on the local population (United Nation Development Assistance framework- UNDAF, 2009).

Hence, in this paper we aim firstly to shed light on results based management concept and techniques. Secondly, to suggest a strategic framework for RBM application into the public sector. Thirdly, to analyze the conventional public administration nature in Egypt; and to identify the challenges facing the application of such suggested results based management framework in Egypt. Finally, to prescribe the different reforming pillars; representing opportunities necessary to transform the Egyptian traditional ineffective public administration into effective development administration applying the recent new public management principles and techniques (NPM); able to adopt a generic framework for results based management into its public sector in order to yield the intended good governance. 


\section{2- Results based management to the public sector: concept and techniques}

In 2000 the UN adopted a modified version of the OECD definition of RBM: "RBM is a management approach focused on achieving results; a broad management strategy aimed at changing the way agencies operate, with improving performance (achieving results) as the central orientation" (Werner Meier, 2003). Thereby, results based management is not the same as management by objectives (MBO); whereby MBO works best with centralized organization and assumes full organizational control over outcomes, and fixed relationships between inputs and outputs. In contrast, results management works best in decentralized organizations operating in a dynamic environment. Also, results based management is not the same as traditional program evaluation; whereby such traditional performance evaluation are generally completed after a project or program is completed. Findings are not fed back into the organization as part of iterative responsive decision-making process. In contrast, for result management real-time feedback loop is integral to its work. Whereby, it plays a key role in supporting result oriented decision making. Meanwhile, results management differs from the logic framework approach (LFA) adopted by the united state agency for international development (USAID) in the early 1970s. Since then, such approach is used as a planning and management tool for many development agencies. In the context of results management modifications for the original logical frame are required; particularly as stakeholders understanding of the causal relationships between expected results and underlying assumptions and risks are elaborated. This dynamic element is generally absent in the traditional logic framework approach (Asian development bank, 2006).

Hence, Results-based management to the public sector is a management strategy by which all actors on the ground, contributing directly or indirectly to achieving a set of development results, ensure that their processes, products and services contribute to the achievement of desired results (outputs, outcomes and goals). RBM rests on clearly defined accountability for results and requires monitoring and self-assessment of progress towards results, including reporting on performance. RBM is seen as a life-cycle framework starting with elements of planning and budgeting such as setting the vision and defining the results framework (as seen in figure 1). Once it is agreed to pursue a set of results through a program, implementation starts and monitoring becomes an essential task to ensure results are being achieved. Finally, monitoring and evaluation provide invaluable information for decision-making and lessons learned for the future (United Nations Development Group- UNDG, 2010). 


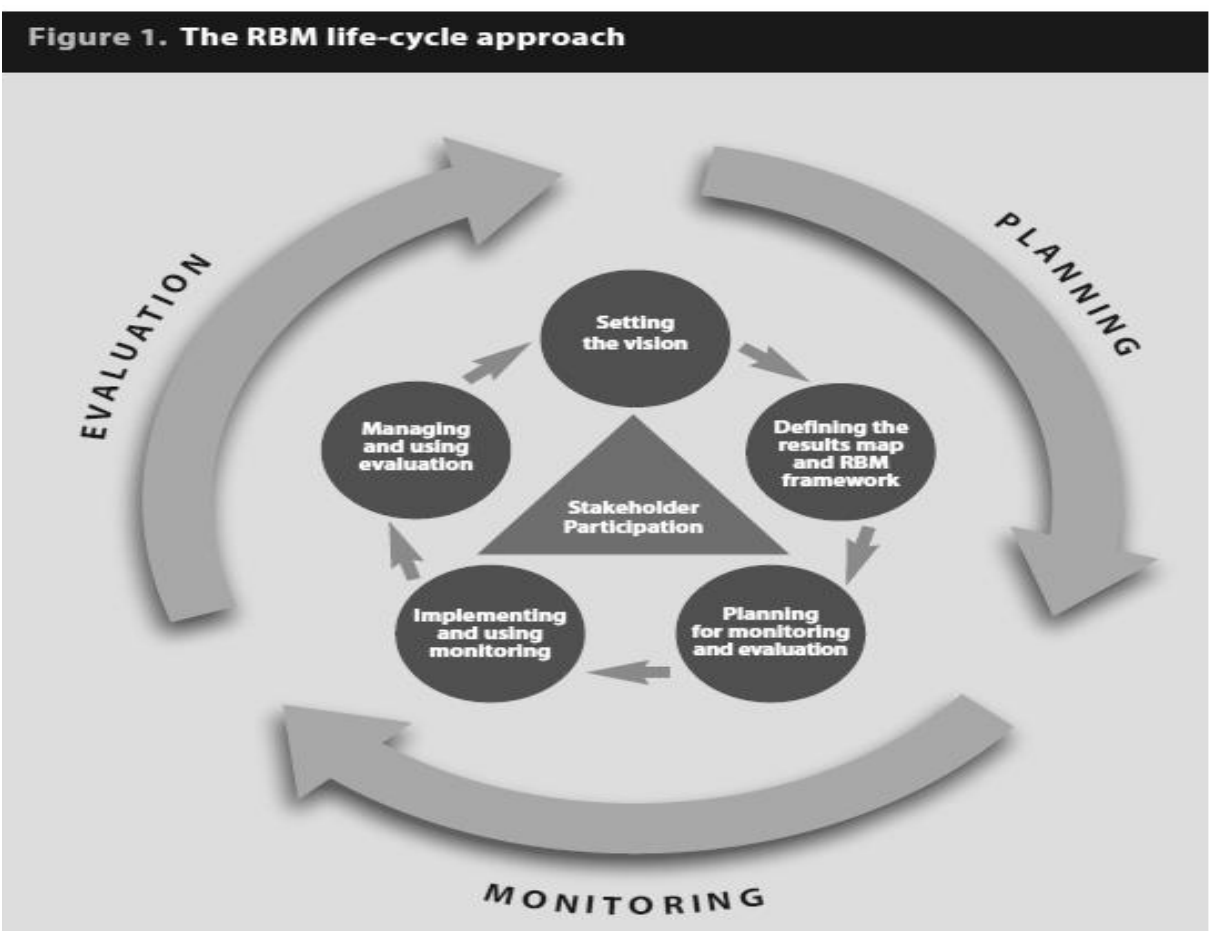

Source: UNDP, Handbook on Planning, Monitoring and Evaluating for Development Results, 2009.

Consequently, Results-oriented public sector management (PSM) features are (Asian Development Bank, 2011):

- Core results attributes

- A focus on common results

- Interdependency and collaboration

- Vertical and Horizontal linkages/partnerships.

We will discuss each one of such features in details as follows:

\section{- Core results attributes:}

The result based management framework identifies core results attributes for each public sector management (PSM) component as follows (McKenzie, Alexander, 2008):

- Results-based planning involves rigorous analysis of intended results cascaded down from macro-level impacts, such as increased employment, to specific sector outcomes, such as increased literacy. These results must be clearly defined within a budget envelope, with indicators and targets, and with relevant monitoring and evaluation frameworks.

- Results-based budgeting ensures that the budget is formulated to deliver the results specified in planning. Results-based budgeting systems ideally produce multiyear budgets (consistent with the medium-term expenditure framework) to align with the planning time 
horizon.

- Results-based implementation means that the people, policies, and processes are effective, efficient, and economic in delivering the intended activities and services.

- Results-based monitoring means that specific parties are responsible for checking performance against the indicators specified in planning, using defined methodologies for data processing, analysis, and reporting.

- Results-based evaluation involves specific parties and stakeholders in assessing the achievement of the targets set in planning, using defined methodologies.

\section{- A Focus on Common Results:}

The same set of nationally owned priorities and results should link all the components through the PSM cycle. That is, the results (impact, outcomes, and outputs) defined during planning must be the same results that are budgeted, delivered, monitored, and evaluated (UNDG, 2010).

Otherwise, planning for results can become simply a top-down compliance document that ignores fiscal parameters, an output-based budgeting system can allocate resources to objectives not linked to the national plan, and the monitoring process can monitor indicators that provide no information on how to evaluate national objectives.

\section{- Interdependency and collaboration:}

These components must also be interdependent - for example, top-down planning sets the policy parameters for budgeting but is in turn influenced by budget limits; during implementation, planning targets are reviewed and the budget is often reassessed to reflect the findings of monitoring; and so on. Collectively, these components must work together in an integrated way to deliver and measure the achievement of national objectives. When this integration happens, future decisions are better informed, enabling continuous learning and the strengthening of the cycle - both for individual components and their linkages. There are also lessons for capacity development: there is little point in focusing on a single component and leaving the others unable to work in a complementary way. Similarly, the Framework allows for any component to be an entry point for reform as long as these interdependent linkages are supported (Mayne, John, 2007).

\section{- Horizontal and Vertical Linkages/partnerships:}

Results-oriented PSM efforts at the national level must be linked with the results-oriented efforts of agencies at the national level - that is, the national development goals must be translated into specific agency priorities, making all of these institutions collectively responsible for achieving results through effective coordination. Sub-national levels of government (regions, districts, provinces, etc.) also play a significant role in achieving country results (Ortiz, E., Kuyama, S. \& others, 2004a).

For this reason, results-oriented PSM efforts at the national level must be linked with those stakeholders at sub-national levels by creating effective partnerships; so that all levels of 
government contribute to delivering a common set of development results. This means that sub-national governments must have the responsibility to develop and implement their own strategic plans within the overall national policy framework, and this responsibility must be matched with clear accountabilities, predictable resources, and sufficient fiscal authority to finance program delivery. These horizontal and vertical linkages enable better attribution and contribution to nationally defined results, and ensure that initiatives in various agencies and at various levels of government complement each other (OECD, 2000).

Then, the result based management framework embodies the logical approach to cause and effect; whereby it illustrates the causal relation among its different elements. The basic rationale is to plan from right to left by initially focusing on impacts and intended outcomes and then identifying the outputs, activities and inputs required to achieve them (as seen in figure 2). Tracking performance then goes from left to right, feeding information back to inputs and activities to make necessary adjustments and improvements, thus leading to better results (Werner Meier, 2003).

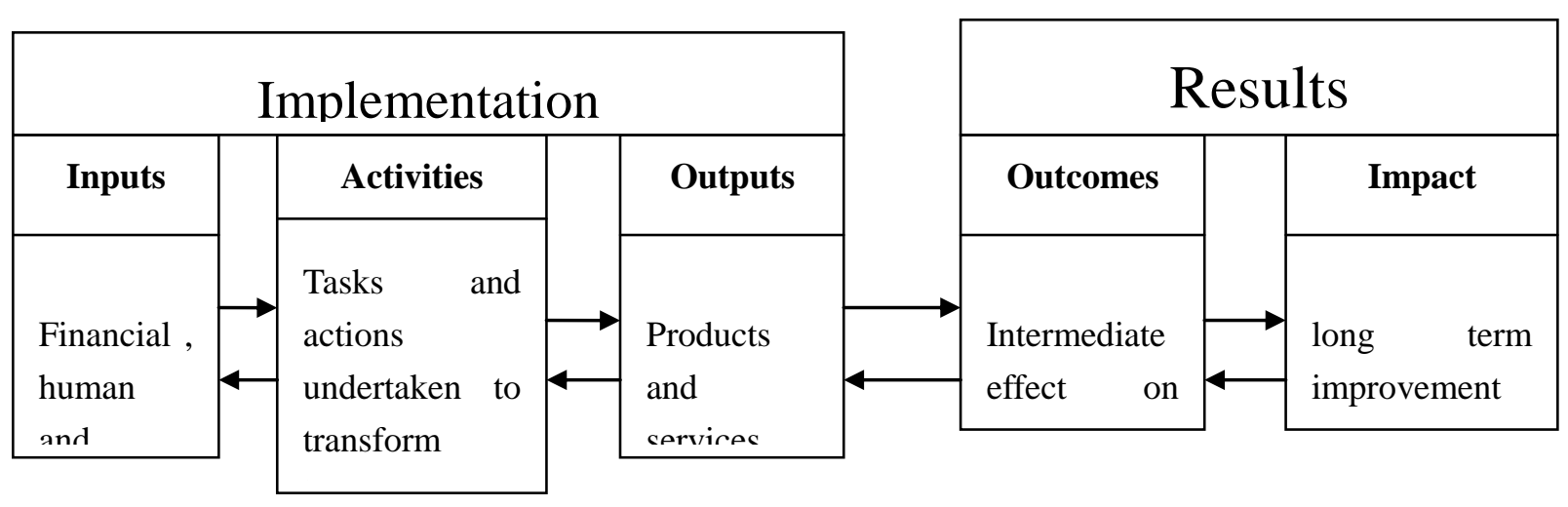

Fig 2: The results chain

Hence, some important principles/prerequisites are required for government organizations to contribute effectively to managing for results (Gavin Lawrie \& others, 2005):

- Foster senior-level leadership from all organizations with national actors playing a major lead in results-based management.

- Promote and support a results culture, particularly:

-informed demand for results information;

-supportive country/national systems,

-a results oriented accountability regime and;

-fostering learning and adjusting;

-clear roles and responsibilities for RBM. 
- Build results frameworks with clearly defined ownership/partnership on the part of national actors at all levels of the government.

- Measure sensibly and develop user friendly RBM information systems relying on complete transparency.

- Use results information for learning and managing, as well as for reporting and accountability.

- Build an adaptive and RBM regime through regular review and updating of frameworks.

Consequently, it is important to mention hereby that the government by adopting a result based management framework; will find itself applying simultaneously the good governance indices such as clear aggregated accountability systems, effective partnerships and fluid transparency.

Finally, we aim by adopting a result based management framework in the public sector; to create a government able to (Osborne \& Gaebler, 1992) (Hassan, A. G. Ouda, 2015):

- Manage for results instead of focusing on inputs, processes and compliance;

- Focus on creating value for available resources instead of spending available resources;

- Budget for results (outputs/outcomes), not inputs;

- Shift accountability for inputs to outcomes or results;

- Manage total economic resources not cash flows and cash balances;

- Measure the operational performance in terms of the three ES (efficiency, effectiveness and economy), not compliance with rules, regulations and procedures;

- Audit the performance of government not the legality and regularity of disbursement;

- Report on total economic resources and performance of government instead of reporting on monetary position of government;

- foster closer link between strategic planning, policies, budgeting, financial management, performance management systems;

- Realize the centralization of objectives and decentralization of management. Government needs to centralize in order to decentralize.

- Encourage collaboration between and within departments.

- Link resources with results to improve budgeting decisions. 


\section{3- A suggested Result Based Management framework to the public sector}

Using the identified features and core results attributes, a country's planning, budgeting, implementation, monitoring, and evaluation and their linkages are reviewed. The component that is most aligned to the identified results attributes is considered the strongest component in the country context. The application of such strategic Framework in a country context, as in the case of Egypt, does not claim to be a scientific assessment of a country's results orientation. While there are identified results-oriented features and attributes, these principles may be applied in any country, form of government, or level of development. Performance based on these attributes is not meant to be compared across countries. Identifying the strengths and weaknesses of the country's PSM cycle shows which components and linkages may need further support and which may be built on in future reforms. It highlights where reforms may be needed to complete the cycle for continuous learning (Andersen, H. V. \& others, 2002).

Hence, there are five cycled steps to managing for results that constitute the RBM strategic framework (as seen in Figure 3). This framework will be described step-by-step as follows:

\section{a- Strategic planning, resources allocation and budgeting}

As part of the public sector management evolution, governmental organizations and agencies are now committed to strategic planning. Initially, all the stakeholders relating to any public issue had to agree on a common vision. Then, it is important to carry out a comprehensive scan of the organization concerning of such public issue (education, healthcare...) to understand the internal (organizational) and external environments as fully as possible. SWOT analysis (strength, weaknesses, opportunities and threats) is one of the prominent method used to address key questions regarding the organization status quo, its mission and strategic goals for the future (results) and how they can be realized; taken into consideration its strengths points (competitive advantages/core competencies), its weaknesses points (lack of some resources), the opportunities that it can exploit in its surrounding environment to enhance the likelihood to reach the organization future aims/results and the external threats that it may face in such attempt to realize its results (Irwin, D., 2002). The precise form taken by strategic planning will vary according to the organization's culture, leadership, complexity, size and mission. Strategic planning for results requires particular attention to linkages between strategic objectives of planning and the bottom line budget. Such budget shows what financial resources are required to implement the plan, how will the money be spent and how will the expended financial resources contribute to desired results (UNDP, 2009).

\section{b- Selecting targets and indicators}

The first step in putting the strategy into action is to develop targets and indicators at all organizational levels (top management/strategic, middle range management/tactical and first line of supervisors/operational) as they are the keys to know when you are making measurable progress toward desired results. This process is interpreted in the results chain mentioned earlier in this paper- which provides an overview of cause and effect relationships and allows differentiation of inputs, processes, outputs and outcomes (Kennerley, M \& others, 
2000). By understanding these relationships, it becomes easy to develop appropriate and reliable indicators that can measure progress on a quantitative scale. Examples include literacy rates, agricultural productivity/crop and so forth. In each case, the indicator measures progress towards the outcome reflecting the desired result. it is important to mention hereby that a solid data baseline is essential for setting explicit targets; whereby particular values for an indicator to be achieved within a clearly defined timeframe. Hence, indicators had to be based on valid and reliable data; that are useful to managers (UNDG, 2007b). Indicators should conform to the "SMART" paradigm: specific, measurable, attainable, realistic, time-bound. When these criteria are met well-informed management decisions -concerning targets and indicators- can be made.

\section{c- Establishing the governance structure for implementation}

It is important to reach consensus on responsibility and accountability at all organizational levels before implementing the result-oriented strategy. Then, if employees are to be held accountable for the results they achieve; they must be clearly empowered and given the authority they need to get the job done. Such empowerment is generally achieved by human resource management that allows for flexibility in determining how the employees do their jobs and also giving priority to measuring, monitoring, evaluating and managing results (Rigby, D. K., 2001). Also, the implementation of partnership-based Action Plans requires adjustments in standard operating procedures and, oftentimes, some institutional reorganization. Pre-existing administrative procedures, divisions of responsibility among departments, contract arrangements, and other practices must be adjusted to allow for the active participation of service users and partner institutions in the implementation of an Action Plan (UNDAF Action Plan guidance, 2009).

\section{d- Monitoring, measuring and analyzing the performance results}

Effectively implementing results based management requires that performance be measured at all levels of the organization. Monitoring begins during the implementation phase; not afterward. Monitoring systems should be designing using available data while avoiding duplicating other management systems. It is also important to determine the frequency of monitoring. Accurate documentation of both implementation activities and their impacts should be kept regularly, in order to allow for the evaluation of action strategies, service approaches, and their impacts on local conditions (Ortiz, E., Kuyama, S. \& others, 2004b). Such documentation is extremely valuable, and at times necessary, to identify the causes of problems that arise during the institution of new service approaches. Measuring and monitoring data involves an iterative process of assessment, comparison and interpretation. After the data are analyzed, results must be interpreted with specific reference to whether desired results are being achieved or not (Wang, X., 2002).

\section{e- Evaluating results and getting feedback}

Monitoring is primarily useful for internal management purposes. Evaluation and feedback are used for both internal and external purposes. It is necessary to maintain accountability among the stakeholder participants in the implementation of an Action Plan. Evaluation, 


\section{Macrothink}

reporting and feedback are also used to inform the general public about progress in meeting specific targets and results, and to signal when the Action Plan must be altered in the face of change (UNDG, 2007a). An effective evaluation, reporting and feedback systems provide regular information to both service providers and users about important changes in local conditions and progress towards targets/results; with this information, the actors can adjust their own actions and behaviours (Jody Zall \& others, 2004). Evaluation information is used to guide planning and resource allocation (budgeting) processes so that these processes are kept accountable to the organization/community vision and its action objectives and intended results. If an Action Plan fails to correct problems or to satisfy prioritized needs, the feedback system triggers further planning or actions (UNIFEM, 2008).

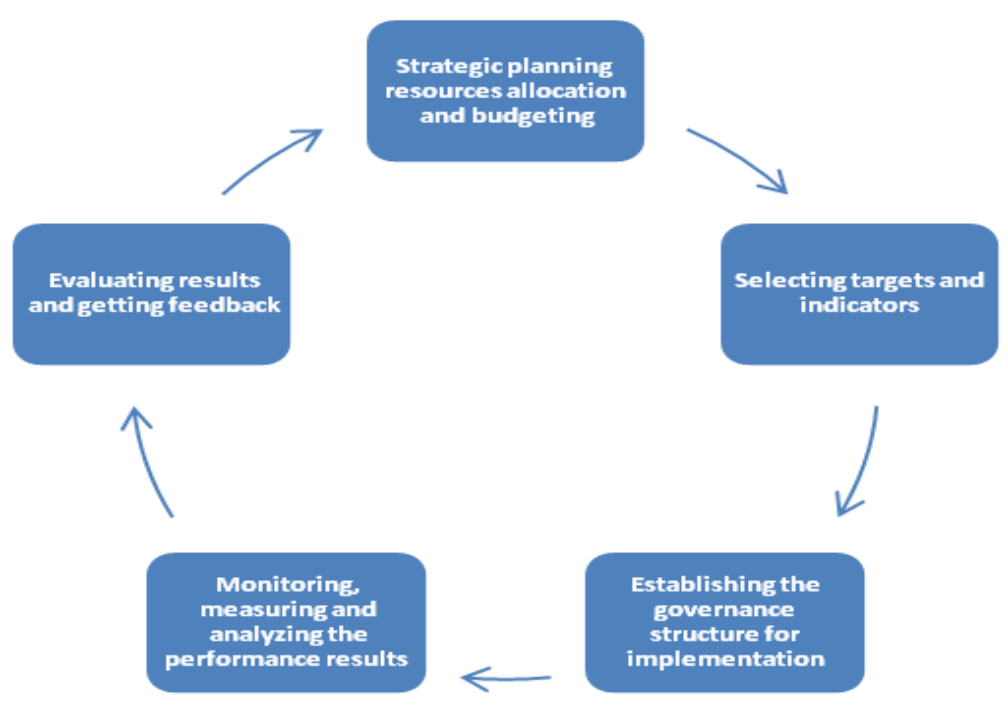

Fig 3: RBM strategic framework

\section{4- Conventional public sector context in Egypt: challenges to results based management framework adoption}

For more than fifteen years, there has been constant pressure on governments around the world for greater transparency and accountability by taxpayers for the use of public resources. Public concern in the face of escalating national account deficits, a declining confidence in political leadership and the need for a more transparent and accountable governance have all been important factors contributing to the emergence of RBM in the public sector (Diamond, L., 2008). Several books have documented the emergence of this new public sector management approach now prevalent in many OECD countries. Historically, the Egyptian government focused their attention on human, technical and financial resources provided as inputs for their programs. The modern management agenda calls for a major shift in focus where public service managers are expected to define expected results, focus attention on result achievement, measure performance regularly and objectively, learn from performance information, make adjustments and improve the efficiency and effectiveness of their 
programs (Denhardt, Janet V.\& others, 2009). However, implementation of the RBM approach in government has been incremental and not without its challenges and disappointments, which central agencies have aptly documented (Sarker, A. E, 2006).

Unfortunately, the public sector in Egypt served as an indispensable arm of the Egyptian regime. It ensured stability and order, produced and distributed public goods, punished the enemies of the regime and maintained its grip on power through rigging elections. The bureaucracy maintained its supremacy in licensing, establishing and monitoring private enterprises, and NGOs. In such a context, it was not possible to establish partnerships between government, private sector and civil society that could create developmental coalitions In light of the above, one can say that Egypt introduced a good example of 'apathetic bureaucracy'( Wael Omran, 2013).

In a survey about bureaucracy in Egypt, the results showed that decentralization and delegation of authority are absent. The authoritarian political regime had deliberately created a highly centralized public bureaucracy (Yassin, E., 1994; PP.65-106); where citizens faced time-consuming processes in public organizations due to the top-down bureaucratic system (Al Masry, 1997; PP.16-17). For decades, the authoritarian political regime in Egypt had deliberately created a highly centralized public bureaucracy; where citizens faced time-consuming processes in public organizations due to the top-down bureaucratic system. Such deplorable bureaucracy maintains its rigidity via mechanistic centralized structure, complicated rules and long detailed procedures. Whereby such rigid bureaucracy is operated by mediocre dissatisfied public employees; suffered from lack of efficient training and effective incentives structure, resisting any reforming attempts -such as results management application- to protect their power and corrupted self interests (Sameh Fawzy, 2012).

Consequently, people were whining for a long time about the decay of public service quality in Egypt; which came to symbolize the decay of the regime itself and its disconnect with the people needs. The inability of public bureaucracy to perform its duties coincided with a noticeable deterioration in the performance of non-state actors and the private sector. This supports Fukuyama's argument that there is a direct relationship between governance and public culture, in that the accountable and transparent government helps disseminate positive public values in other society organizations (Fukuyama, F., 2004; PP.39-41). The bureaucracy maintained its supremacy in licensing, establishing and monitoring private enterprises, and NGOs. In such a context, it was not possible to establish partnerships between government, private sector and civil society that could create developmental coalitions (Hyden, G., 1997; P.30).

Hence, we can aggregate the main Challenges to the adoption of RBM framework in the Egyptian public sector as follows:

\section{- Absence of Basic Public Management Processes}

New public management (NPM) in developed countries is typically used to improve existing institutions where the bureaucracy is meanwhile aware of basic public management processes; but the processes like solid institutional frameworks, rule of law, proper control 
structures, checks and balances, the civil service system, and accountability systems are either absent or ineffective in Egypt (Wael Omran, 2014).

Despite having good intentions, the country has failed to change the precepts of classical organization theory as a way of reinventing government like western administration. Whereby the Traditional public sector systems' for administration, budgeting, Performance measurement and Auditing in Egypt are no longer able to measure whether the government has efficiently and effectively used the resources entrusted to it; whether the appropriations have been used to produce the outputs that are required to achieve the outcomes. As the old command-and-control system in the bureaucratic management regime, gave the Public Sector Managers the message that risk would not be rewarded, that inefficiency would not be penalized, that what mattered most was complying with the current procedures, rules, and regulations (Scott, 1996).

Hence, under the traditional public administration systems in Egypt, the Managers are most concerned about the compliance with rules and restrictions and they are not accountable for results. NPM strategic management, performance management, etc., can be effective only when the basics of administration are in place (Hood, C, 2001). In this respect, Egypt public administration has demonstrated its deficiencies in establishing a rule-based system and enforcing a control structure, resulting in numerous dysfunctional consequences that hinder the adoption of RBM in the Egyptian public sector.

\section{- Resistance to change of Bureaucrats}

The organizational culture promoting for cooperation, support and activities of the public bureaucracy play a crucial role when the particular government keeps the RBM-style reform on the table. The reforms have unfortunately faltered in Egypt for lack of appreciation and support by the civil servants who are responsible for implementing reforms. Most bureaucrats' organizational culture resort to a protectionist attitude toward the insertion of RBM; whereby, they always consider the reform attempts as downgrading their present status, position, and power and create resistance to distract reform activities (Khan 1991; Sarker 2004; World Bank 1996). The tendency of most civil servants to preserve the status quo, and, if possible, extend their zone of influence within the public service system, is very much evident in Egypt.

\section{- Tendency to make complicated RBM frameworks}

One common mistake is to design overly complicated results frameworks with large number of indicators and targets. Even if these are clearly differentiated from one to another, the proliferation of indicators makes monitoring difficult, unfocused and the practical use of the information more difficult (Asian Development bank, 2006).

\section{- Inadequate employees' incentives}

In most traditional public sector organizations as in the case of Egypt, employees' incentives revolve around implementing business processes and ensuring that the organization transforms certain inputs into desired outputs. However, such incentives are not likely to 
motivate employees to make the transition to results management. Such transition requires building newly aggregated systems of rewards and incentives; relying on realistic clear performance indicators linking to results management attributes (inputs, processes, outputs and outcomes) (Barzelay, Michael \& others 1992).

\section{- Insufficient training and organizational support}

In many cases, organizations develop results management systems neglecting the human dimension. The concepts of results management are often new and risky to the employees. Especially, if they are not fully supported with sustainable capacity development programs and reference materials (Ball, I., 1994).

\section{- Lack of Political Foresight and Commitment}

The foresight and commitment of political leadership work as driving forces to implement the RBM model in public/governmental sector. In Egypt, few political governments tried to reform the public administration in order to establish the principles and elements of NPM. The reasons include: a lack of knowledge about NPM and RBM methodologies, the mentality of lengthening the power, the lack of commitment and the fact that political leadership has never been cordial in their attempt to revamp the running system and ensure the outcomes, efficiency, performance and accountability in the public administration (Khan, 1998).

\section{- Incapability of the Governments}

The government needs capacity and concerted efforts to apply NPM model in the public sector through reforms. For decades, almost all governments in Egypt have miserably failed to demonstrate an extraordinary capacity to realize the recommendations of the reform committees. Besides, many factors can be discerned with the limited capacity of government as well. For example, development agencies constantly break rules and regulations to serve sectional interests (The World Bank, 2008). Regulatory agencies responsible for maintaining law and order have not performed according to the letter of the law (CPD, 2001a). As a result, to ensure individual performance, efficiency, effectiveness, outputs and outcomes in public services have been defied at all times.

\section{- Corruption}

Corruption is deeply rooted in all aspects of public administration in Egypt. The whole public administration has been plagued by both political and administrative corruption in a form of bribery, abuse of authority, nepotism, favoritism, patronage, theft, and deceit (Fadel, M, 2011). These phenomena have already emerged as a factor impeding the RBM-style reforms in Egypt.

\section{5- Key Reform Initiatives needed by Traditional public sector of Egypt to adopt the suggested RBM framework}

Making the transformation to true results orientation, via the aforementioned framework, is challenging as technology and management information systems may need to be upgraded, and public employees must greatly improve their knowledge of results management. The 
process of becoming results focused requires a fully managerial reform towards New Public Management application combining with the good governance indices adoption, such as the pervasive accountability, the true transparency and collective participation, the understanding and commitment of top management, a supportive organizational culture, and employees' incentives structure that prioritize achieving results rather than sticking to particular business rules and processes.

In short, results based management framework adoption in the Egyptian public sector requires -as a prerequisite- some important reforming pillars; which represent true opportunities to a successful transformation towards RBM; they are as follows:

\section{- Managerial reform}

The emphasis of the New Public Management movement, a decade or so later, was firmly managerial stressing the management to ensure the quality and efficiency of public services that could ultimately focus on public service production functions and operational issues (Md. Mizanur Rahmani \& others, 2013). NPM system contrasted with the focus on public accountability, 'model employer' public service values, due process, results and what happens inside public organizations in conventional public administration. How far the small-government economic-rationalist agenda that went together with more stress on public-sector management in the 1980s and 1990s was integral to those managerial ideas is debatable (Barzelay, 2000).

However, it is hard to separate these elements since the advent of a new generation of public sector managerialism coincided with concern by numerous OECD (Organization for Economic Co-operation and Development) governments to reduce the power of public service trade unions, increase regulatory transparency and tackle perceived inefficiencies of public enterprises. NPM shifts the emphasis from traditional public administration to public management (Lane, 2000) and also pushes the state toward managerialism (Walsh, 1995). The traditional model of organization and delivery of public services, based on the principles of bureaucratic hierarchy, planning, centralization, direct control and self-sufficiency, as in the case of Egypt, is being replaced by a market-based public service management, or enterprise culture (Caiden, 2001).

Consequently, the intended new public management key elements in Egypt must include various forms of decentralizing management within public services e.g., the creation of autonomous agencies and devolution of budgets and financial control, increasing use of markets and competition in the provision of public services (e.g., contracting out and other market-type mechanisms), and increasing emphasis on performance, outputs, outcomes and customer orientation (Larbi, 1999). Conclusively, the key elements of New Public Management to be applied in Egypt realizing the result based management thinking had to be as follows (Pollitt, 1994) (Lynn, Laurence E., Jr., 1996):

1. A shift in the focus of management from inputs and processes towards outputs and outcomes,

2. A shift towards Budget for results (outputs/outcomes), not inputs. 


\section{MInstitute Macrothink $_{\text {Int }}$}

Journal of Public Administration and Governance

ISSN 2161-7104

2015, Vol. 5, No. 4

3. A shift towards more measurement and quantification, especially in the form of systems of 'performance indicators' and/or explicit 'standards'.

4. A shift towards Audit the performance of government not the legality and regularity of disbursement.

5. More frequent deployment of market-type mechanisms (MTMs) for the delivery of public services (quasi-market solutions, compulsory competitive tendering).

6. Preference of lean/flat and autonomous organizational forms: decentralization (i.e. let the managers manage / the right of managing).

7. Favoring contract-like relationships instead of hierarchical relationships.

8. Client and quality orientation; by generalize the E. government usage to all the public services to ensure a quick responsiveness to people needs and desires.

9. Applying lean thinking methodology to public services; by maintaining an effective value stream of value-added activities to satisfy citizens/clients needs in high quality, lower cost and minimum time.

10. Blurring the boundaries between public, private and non-profit sectors.

11. Value orientation: favoring individualism and efficiency rather than equality and universalism.

12. Adjustment of staffing systems, training and human development sessions to enhance job effectiveness, efficiency and employees' satisfaction. So, the right person who is capable, and convinced to apply the RBM principles and Techniques; will fill into the right post.

13. Create an effective code of ethics that advocates the RBM values and principles, in order to make the organizational culture supportive for RBM adoption within the public sector organizations.

14. Managerial leaders' commitment to apply the RBM framework in the public sector will ease the implementation of RBM processes and procedures; and also will diminish their employees' resistance.

\section{- Legislative and legal reforming:}

Legislations batch must be issued to modify the Egyptian laws for budgeting, governmental accounting, financial and managerial auditing to become outcomes/results oriented instead of being processes/regulations oriented. Also, we had to modify the current civil service laws and also the employment laws in Egypt; to reconsider the current rewards, incentives, promotions and penalties systems to be based on results performance instead of rules/ regulations compliance. Finally, the current laws in Egypt had to be reviewed by legal experts committees; to avoid any legal contradictions that may impede the adaptation of the suggested modifications on the aforementioned laws to the Egyptian socio economical, political and cultural environment. 


\section{- Partnership}

In development co-operation, $\mathrm{RBM}$ has to be built on mutually beneficial partnership relationships based on trust among the stakeholders involved in a development intervention. It is expected that statutory authorities exercise leadership and ownership, while local agencies and other civil society organizations play an actively supportive role. The extent of beneficiary/citizen participation as a partner in the development intervention is encouraged but will vary according to circumstances and the prevalence of good governance and democracy (Kettl Donald F., 2000).

\section{- Accountability}

Determining accountability should take into consideration the nature of the partnerships in the development intervention. Where strong partnerships are present, a development intervention starts with shared performance expectations, continues with shared management decision making and leads eventually to share accountability. Under these ideal circumstances, statutory authorities, local agencies and various civil society organizations could assume shared accountability for development results when reporting to their respective constituencies (Hodges, R, 2013).

\section{- Organizational Learning}

Organizational learning is the motivation behind the adoption of the RBM approach by highly effective organizations. RBM facilitates organizational learning by channeling performance information to decision-makers through nested feedback loops from continuous performance monitoring, evaluation and audit activities. This creates opportunities for learning at the individual, group and system level to continuously transform the organization or development intervention in a direction that is increasingly satisfying to its stakeholders. Management decision-making processes can then be informed by valid and reliable performance information; that yield to greater efficiency and effectiveness (Peters, B. Guy, 1994).

\section{- Transparency}

Transparency is necessary to ensure that the benefits of the above RBM principles are fully realized. Clarity is needed in defining the respective roles and responsibilities of partners for the development intervention, and specifically the implementation of the RBM approach. Appropriate disclosure of the methodologies used to collect valid and reliable performance indicator data is critical to fulfilling partners' accountability obligations for reporting to their respective constituencies (Caiden, N., 1998). Broad dissemination and active discussion of performance information, via various social media means, including progress made toward the achievement of outcomes, lessons-learned and proposed adjustments, will enhance national country ownership and organizational learning. The RBM approach is significantly weakened in an environment that lacks transparency (Summa \& Waerness, 1999).

\section{- Simplicity}

Simplicity is one of the keys to successful RBM implementation. Rather than focusing on a 
core set of expected results, the tendency has been to design complex results chains with numerous and finely differentiated outputs, outcomes and impacts. Of course, this increases the number of performance indicators required to produce reliable performance information by an exponential factor. Before too long data collection, analysis and reporting have absorbed a disproportionate amount of resources and management attention (Kathryn Newcomer \& others, 2000). The key is to keep the results and indicators to the vital few for continuous monitoring across the entire results chain from inputs, outputs, outcomes and impacts, and to transform evaluation and internal audits into learning opportunities. So, try to keep it simple, but no simpler than it is (Swope, Christopher, 2001).

\section{- Flexibility}

Like any good management strategy, RBM should be sufficiently flexible to be applied in an iterative manner in a broad range of circumstances. Governments, private agencies and civil society organizations have applied RBM in order to satisfy their unique organizational needs (Gores, Al. 1993). In international co-operation, the RBM experience has been mostly at the project level, but increasingly with program-based approaches, e.g., sector-wide adjustment programs, basket funding, etc. Donor agencies have moved from "blue-print" to iterative approaches in designing development interventions (Werner Meier, 2003). These types of interventions present new challenges that require flexible management approaches, while upholding the other RBM principles.

\section{- Societal and cultural conscious and training:}

Various training programs and media campaigns had to be designed and executed to inform publics and employees about RBM important role in the realization of development objectives and its constructive effects on the community. In order to avoid their potential resistance for RBM adoption in the public sector, and to make individuals and institutions aware about relevant RBM procedures (Moore, Mark, 1995). Hence, Different stakeholders in society such as families, media institutions, various governmental apparatus, religious and educational institutions, and civil society organizations must cooperate together and integrate their efforts. Then, they may be able to create the effective partnership necessary for the application of RBM framework as well as the good governance realization (Schachter, Hindy Lauer, 1995).

\section{- Political commitment}

The foresight and commitment of political leadership had to work as driving forces to build effective networks of partners in a good governance context; to implement effectively the RBM framework in the public sector realizing the sustainable development in the society.

\section{6- Conclusion}

We note after the previous analysis that the public sector in Egypt need to be deregulated, a new results-based management is a must; to hold managers accountable. This is a fundamental change: from accountability in terms of procedural compliance to accountability in terms of efficiency and results (effectiveness and cost effectiveness). Then the government 
will be able to realize effectively its national plan for development and the outcomes/results of its developmental projects will be delivered to the poorest citizens in the country.

Accordingly, by using the identified features and core results attributes, a country's planning, budgeting, implementation, monitoring, and evaluation and their linkages are reviewed. Five cycled steps to managing for results that constitute the RBM strategic framework are suggested to be used in the Egyptian public sector. Such strategic framework will begin firstly with strategic planning, resources allocation and budgeting. Secondly, selecting targets and indicators for the indented performance that yields to the desirable results. Then, the third step is to establish the governance structure for implementation. The fourth step is monitoring, measuring and analyzing the performance results. Finally, evaluating results and getting feedback.

Unfortunately, there are diverse challenges -as we aforementioned- to the adoption of an effective Result based management in Egypt. Such challenges can be abbreviated as: the absence of basic public management processes, resistance to change of bureaucrats, tendency to make complicated RBM frameworks, inadequate employees' incentives, insufficient training and organizational support, lack of Political Foresight and Commitment, incapability of the governments and the corruption.

Consequently, in order to overcome the aforementioned challenges to the adoption of the suggested RBM framework in the Egyptian public sector; it necessitates the adoption of various reforming pillars relying on NPM principle and good governance indices; such pillars are: Managerial reform, legislative and legal reforming, partnership, accountability, organizational Learning, transparency, simplicity, flexible and Iterative Application and societal and cultural conscious and training.

Finally, we assure hereby that the political commitment for reforming is a must; whereby no reforming efforts can success without the political leadership support and people awareness about the importance of reform. The government had to acquire also the necessary financial and technical resources to enhance their reforming program. It can procure such various resources by local funding or by foreign international grants and donations programs.

\section{References:}

- Al Masry, A., The Basic Foundations of the Performance of Public Employee, Al Adara, Vol. 29, No.3, 1997, pp. 14-17.

- Andersen, H. V., and Lawrie, G. J. G, Examining Opportunities For Improving Public Sector Governance through Better Strategic Management. Proceedings, third International Conference on Performance Measurement and Management (PMA), Boston, 2002, pp.22-31.

- Ball, I., "Initiatives in public sector management and financial management: The New Zealand Experience" in Arthur Anderson, "Financieel beheer,verslaggeving en prestatiemeting bij de Rijksoverheid”, Symposium verslag 2 November, Circustheater 
Schevenongen, 1994, pp.101-108.

- Barzelay, M., The New Public Management, University of California Press, Berkeley, CA, 2000, pp. 156-172.

- Barzelay, Michael \& Babak J. Armanji, Breaking through Bureaucracy: A New Vision for Managing in Government, Berkeley, CA: University of California press,1992, pp. 65-78.

- Caiden, G.E, Administrative Reform, Handbook of Comparative and Development Public Administration, New York: Marcel Dekker, 2001, pp. 655-688.

- Caiden, N., "Public Service Professionalism for Performance Measurement and Evaluation, Public Budgeting and Finance, 18 (2), 1998, p.35.

- Center for Policy Dialogue (CPD), Policy Brief on Administrative Reform and Local Government, CPD Task Force Report, Dhaka: CPD, 2001a, pp. 3- 18.

- Denhardt, Janet V. and Robert B. Denhardt, Public Administration: An Action Orientation, Thomson Wadsworth, 6th edition, 2009, pp, 410-411.

- Diamond, L., The Spirit of Democracy: The Struggle to Build Free Societies Throughout the World, New York: Times Books, 2008, pp. 101- 119.

- Fadel, M., Public Corruption and the Egyptian Revolution of January 25: Can Emerging International Anti Corruption Norms Assist Egypt Recover Misappropriated Public Funds? Harvard International Law Journal Online, Vol. 52, 2011, pp. 11- 19. www.harvardilj.org/online/ (accessed 5 October 2011).

- Fukuyama, F., State Building, Governance and World Order in the Twenty First Century, London: Cornell University Press, 2004.

- Gavin Lawrie, Dirk Kalff \& Henrik Andersen, Balanced Scorecard and Results- Based: Management Convergent Performance Management Systems, Presented at 3rd Annual Conference on Performance Measurement and Management Control, The European Institute for Advanced Studies in Management (EIASM), Nice, France, September 2005, pp.1-17.

- Gores, Al., From Red Tape to Results: Creating a Government That Works Better and Costs Less, Report of the National Performance Review, New York: Times Books, 1993, pp.13-16.

- Hassan, A. G. Ouda, Results Based Systems Are The path Towards Results Oriented Government, International Journal on Governmental Financial Management, Vol. 15, No.1, 2015, pp. 46-66.

- Hodges, R, Accountability and Accounting for PPPs, chapter 18, forthcoming in de Vries, $\mathrm{P}$ and Yehoue, E. (eds.), The Routledge Companion to Public Private Partnerships, (Routledge, Washington DC), 2013, pp.169-174.

Hood, C., Public Management, New, International Encyclopedia of the Social \& 
Behavioral Sciences, Elsevier Science Ltd, 2001, pp.188-219.

- Hyden, G. 'Building Civil Society at the Turn of the Millennium', in John Burbidge (ed.), Beyond Prince and Merchant. Citizen Participation and the Rise of Civil Society, New York: Pact Publications, 1997.

- Irwin, D. Strategy Mapping in the Public Sector. International Journal of Strategic Management, Vol. 35, number 6, 2002, pp. 563-672.

- Jody Zall Kasek \& Ray. C. Rist, Ten Steps to A Results Based Monetary and Evaluation System, The World Bank, 2004, pp. 23-27.

- Kathryn Newcomer and Aaron A. Otto, Is Government performance result act (GPRA) Improving Federal Government?, Public Administration times, Vol. 23, No.1, 2000, pp.1-6.

- Kennerley, M. and Neely, A. D., Performance Measurement Frameworks, A Review Proceedings, 2nd International Conference on Performance Measurement, Cambridge, UK, 2000, pp.3- 23.

- Kettl Donald F, The Transformation Of Governance: Globalization, Devolution and the Role of Government, Public Administration Review, Vol. 60, no. 6, 2000, pp.488- 497.

- Khan, M. M., Politics of Administrative Reform: A Case Study of Bangladesh, New Delhi: Ashish Publishing House, 1991, pp. 25- 45.

,Administrative Reforms in Bangladesh, Dhaka: University Press Limited, 1998, pp. 10- 22.

- Lane, Jan-Erik, New Public Management: An Introduction, Routledge, Available at:http://www.routledge-ny.com/books/New-Public-Management-isbn9780415231862, 2000, pp. 28-36.

- Larbi, George A., The New Public Management Approach and Crisis States, UNRISD Discussion Paper, No. 112, Geneva, Switzerland, 1999, pp. 2- 15.

- Lynn, Laurence E., Jr., Public Management as Art, Science and Profession, Chatham, NJ: Pittsburgh, PA University of Pittsburgh Press, 1996, pp.35-39.

- Mayne, John. Best Practices in Results-based Management: A Review of Experience. A Report for the United Nations Secretariat, Volume 1: Main Report., July 2007, pp. 2-26.

- McKenzie, Alexander, Results-based Management at the Country level: Systemic issues at prevent good UNDAF results and the use of UNDAF results information, UN Working Group on Programming Policies, September 2008, pp.4-32.

- Md. Mizanur Rahman, Leslie Sue Liberman, Vincentas Rolandas Giedraitis \& Tahmina Akhter, The Paradigm from Traditional Public Administration to New Public Management System in Bangladesh: What Do Reform Initiatives Stand for? Advances in Economics and Business 1(3), 2013, pp. 297-303. 
- Moore, Mark, Creating Public Value Strategic Management in Government, Cambridge, MA: Harvard University Press, 1995, pp.46-51.

- Nagy Hanna \& R. Piccotto, Making Development Work: Development Learning in a World of Poverty and Wealth, World Bank series on Evaluation and Development, Vol.4, pp.226-229.

- Organization of Economic Co-operation and Development (OECD), RBM in the development cooperation agencies: a review of experience, Development Assistance Committee paper, Feb 2000, PP. 32-46.

- Ortiz, E., Kuyama, S., Munch, W. and Tang, G., Overview of the Series of Reports on Managing for Results in the United Nations System. UN Joint Inspection Unit, 2004a, pp. $2-44$.

Implementation of Results-Based Management in the United Nations Organizations Part 1. UN Joint Inspection Unit, United Nations, 2004b, pp.12- 31.

- Osborne, D. \& Gaebler, T, Reinventing Government: How the Entrepreneurial Spirit Is Transforming the Public Sector, Reading, MA: Addison-Wesley, 1992, pp. 120-121.

- Peters, B Guy., New Visions of Government and the Public Service, In New Paradigms for Government: Issues for the Changing Public Service, edited by Patricia W. Ingraham and Barbara S. Romzek, San Francisco: Jossey-Bass, 1994, pp. 33-42.

- Pollitt, C., Modernizing the Management of the Public Services Sector: Between Crusade and Catastrophe?" Paper Presented to the Administrative Development Agency, Helsinki, Finland, 1994, pp. 23-42.

- RBM-UNFPA Training Manual, United Nations Development Assistance Framework, Guidelines for UN Country Teams on preparing a CCA and UNDAF, UN Common Country Assessment, Draft, October 2009. pp. 3-42.

- Rigby, D. K. Management Tools and Techniques: A Survey. California Management Review, Vol.43, No.2, 2001, pp. 8-24.

- Sameh Fawzy, Accumulative Bad Governance, IDS Bulletin, Volume 43, Number 1, Blackwell Publishing, January 2012.

- Sarker, A. E., Administrative Reform in Bangladesh: Three Decades of Failures, International Public Management Journal, Vol. 7, No. 3, 2004, pp. 67-79.

, New Public Management in Developing Countries: An Analysis of Success and Failure with particular reference to Singapore and Bangladesh, International Journal of Public Sector Management, Vol. 19, Issue-2, 2006, pp.180 - 203.

- Schachter, Hindy Lauer, Reinventing Government or Reinventing Ourselves: Two Models for Improving Government Service, Public Administration Review, vol. 55, no.2, 1995, pp. 530-537. 
- Scott, G. , "Government reform in New Zealand", International Monetary Fund, Washington,1996, pp. 12-16.

- Summa and Waerness, Performance audit and public management in five countries and Public management reform: a comparative analysis, Oxford University Press, 1999, pp. 248-250.

- Swope, Christopher, Restless for Results, Governing Magazine, April, 2001, p.20-23.

- The Asian Development Bank (ADB), A Framework for Results-Based Public Sector Management and Country Cases, This report was prepared by consultants in close cooperation with partner countries supported by the technical assistance project RETA 7744: Asia-Pacific Community of Practice on Managing Development Results - From concept to Practice, September 2011, pp. 3- 46.

Management: Principles, Implications and Applications, 2006, pp. 5-37.

- The World Bank, Egypt - Development policy review, Social and Economic Development Group, Middle East and North Africa Region, May 15, 2008, pp. 8- 18.

- UNDG, The Role of Evaluation in RBM, Final Report, August 2007a, pp. 11-22.

- _ _ _ Indicators, Draft Technical brief: Updated October 2007b, pp. 2-32.

- $\quad$, UNDAF Action Plan guidance FINAL DRAFT, Comments collected by 9 October 2009, pp. 10-19.

- _ , Results-Based Management Handbook Strengthening RBM harmonization for improved development results, The Handbook is spearheaded by the RBM/Accountability Team, March 2010, PP.2- 38.

- UNDP, Handbook on Planning, Monitoring and Evaluating for Development Results, 2009, pp. 4-24. See also: www.undp.org/eo/handbook.

- UNIFEM. Monitoring, Evaluation and Knowledge Management Framework, UNIFEM, August 2008, pp. 22-34.

United Nations Development Assistance framework (UNDAF), November 2009, pp. 5-18

- Wael Omran Aly, Bad Governance and Failure of Development Progress in Egypt: Causes, Consequences and Remedies, Journal of Public Administration and Governance, Vol. 3, No. 4, 2013, pp. 39-59.

Performance in Egypt: Challenges and Opportunities, Journal of Public Administration and Governance, Vol. 4, No. 2, 2014, pp. 90- 105.

- Walsh, K., Public Services and Market Mechanisms: Competition, Contracting and the New Public Management, London: Macmillan, UK, 1995, 110-143. 
- Wang, X., Assessing Performance Measurement Impact: A Study of U.S. Local Governments, Public Performance \& Management Review, vol. 26, no. 1, 2002, pp. 26-43.

- Werner Meier, Results-Based Management: Towards a Common Understanding Among Development Cooperation Agencies Discussion Paper, Ver. 5, Prepared for the Canadian International Development Agency, Performance Review Branch, for consideration by the DAC Working Party on Aid Effectiveness and Harmonization, October 15, 2003, pp. 5-35.

- Yassin, E. (ed.), Egyptian Bureaucracy, an Empirical Study, Cairo: Al Ahram Center for Political and Strategic Studies, 1994, pp. 12-15. 